\title{
Network Selection Algorithm at the Starting Point of Mobile Device in Indoor Wi-Fi Environment
}

\author{
Hyun-Jun Shin, Min-ho Jeon and Chang-Heon On \\ Korea University of Technology and Education, Electrical, Electronics and \\ Communication Engineering, Cheonan, Korea \\ champ5866@koreatech.ac.kr,w1004me@koreatech.ac.kr, choh@koreatech.ac.kr
}

\begin{abstract}
In the location estimation technology using WLAN, RSSI coming from each AP has a large deviation due to complicated and varying indoor environments. Especially when a laptop is used for work inside a building or when a location-based service is required, the AP needs to be changed depending on RSSI coming from the laptop or the type of work. However, most studies are about hand-over technology between different types of devices based on mobile devices with good portability. Hand-over technology is generally controlled and managed at the server to identify the AP information and select a network quickly. Though this is the best choice to select network and connect communication quickly, any mobile device that is not registered in the server cannot be provided with the service.

The current paper proposes a network selection algorithm at the starting point of mobile device as a way to solve the problem through simulation and performance evaluation.
\end{abstract}

Keywords: Hand-over, 2.4/5GHz, Dual-Band, Wi-Fi, WLAN, Mobile Device

\section{Introduction}

The primary characteristic of a location-based service (LBS) is that, it can identify the location of a moving object and provide services based on its location. In this context, one major point of concern regarding LBS is the location estimation system. In particular, wide uses of smart devices, application of LBS that uses many access point and other communication equipment that are installed in buildings, enhances LBS primarily with respect to indoor set ups, such as welfare for the disabled or information service of big buildings[1,2].

A representative location-estimation system to identify the whereabouts of a moving object is GPS (global positioning system). Since GPS is a location-estimation system, typically used for outside, it is not appropriate for indoor use due to insufficient visible satellites, weak signals and remarkably poor reception [3]. To resolve such an issue and secure precise location estimation for indoor, ToA, TDoA and fingerprinting techniques have been studied under various conditions [4-6].

Figure 1 shows the accuracy and uses of location-aware technology. Within this technology, the mobile phones, GPS and WLAN have relatively lower accuracy but higher utilization than that of the others. This is because mobile phones and WLAN are widely used communication technology for mobile devices, such as smart devices and laptops that can estimate the location and transmit data. Interestingly, the WLAN-based location estimation technology does not need any new infrastructure and can use the already installed communication network. Moreover, WLAN technology also run both location-based and communication services for laptops, PDAs (personal digital assistant) or devices that are 
installed with wireless LAN card in the application program level. Therefore, much attention is being paid currently to location estimation system, based on WLAN.

Generally, WLAN suffers from large deviations in RSSI, coming from each AP due to complicated and varying indoor environments. For example, when a laptop with the requirement of LBS is used on move in a building, a change in the AP becomes necessary depending on the RSSI coming from the laptop itself.

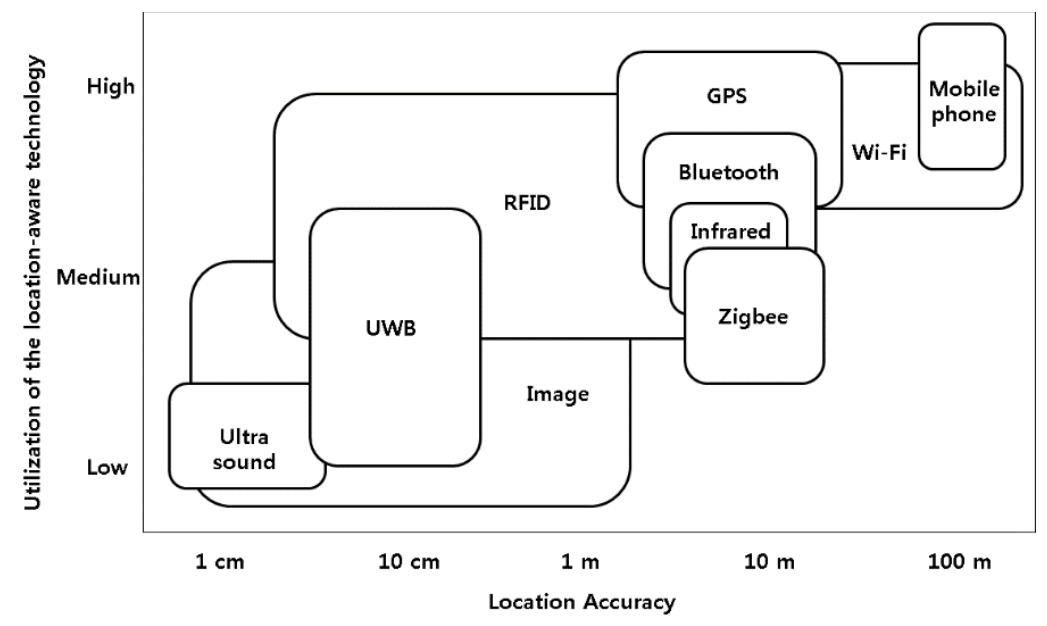

Figure 1. Accuracy and Utilization of the Location-aware Technology

Importantly, most of the reported studies are on hand-over technology between different types of mobile devices with good portability. In this regard, it can be mentioned that, handover technology is typically controlled and managed at a server to identify the AP information and select a network quickly and the technology is the best choice for a fast selection of a network and connection of the same with the communication device. However, any mobile device that is not registered at the server cannot be provided with such service.

To address this issue, the current paper aims to provide a network selection algorithm at the starting point of a mobile device. The suggested network selection algorithm would be able to select the network by using RSSI data collected by the mobile device, and the necessary communication speed of the concerned application program used to receive weak signals.

The organization of the current paper is as follows- Following this introduction in Section 1, Section 2 elaborates the details of hand-over and Wi-Fi dual band technologies. In Section 3 , the operation principle of the suggested technology has been explained. Next, Section 4 analyzes the test environment and performance of the suggested technology, which is finally followed by conclusions in Section 5.

\section{Related Works}

\subsection{Hand-over}

Hand-over is the core technology of cellular tele-communications, which retain current service continuously in existing section even if the subscriber moves to other adjacent cell from the current cell of the subscriber. Hand-over is generally classified into inter-cell handover, intra-cell hand-over and inter-system hand-over depending on the coverage. Intercell handover, also called as soft hand-over, occurs in the inside of one cell, which means 
switching of channels that are used in the current terminal-located cell coverage. Intra-cell hand over has been used since the use of IS-95 CDMA (code division multiple access) system. The most general hand-over is the soft hand-over and it is connect before break type inter-system hand-over is not the handover by call transfer like between hierarchical handovers in hierarchical cell structure but the handover is to take control over to other stratified base station for more effective call processing $[6,8]$.

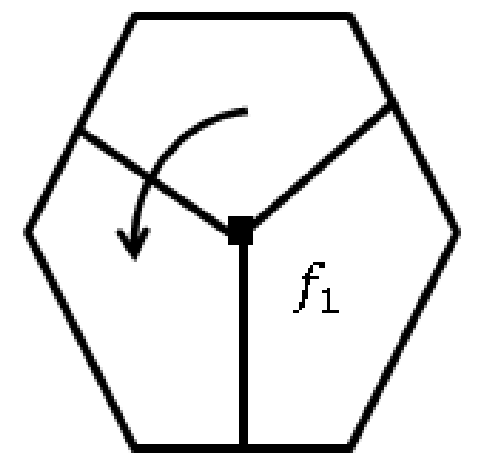

(a) Soft Handover

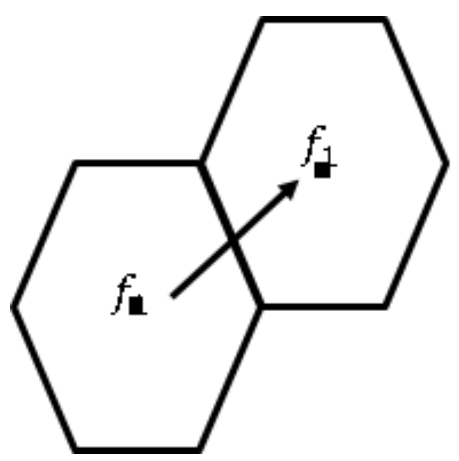

(b) Soft Handover

Figure 2. The Handover Technique

\subsection{Wi-Fi Dual-band}

Table 1 shows the available Wi-Fi channel frequencies for $2.4 \mathrm{GHz}$ and $5 \mathrm{GHz}$ bands. 2.4 $\mathrm{GHz}$ band has 13 channels and $5 \mathrm{GHz}$ band has 24 channels. The 13 channels of $2.54 \mathrm{GHz}$ are arranged in order of frequencies, however, the 24 channels of $5 \mathrm{GHz}$ are not arranged in order of frequencies and overlapping of frequencies occur, creating interference problems. Wi-Fi 802.11 standard briefly specified 5 standards, viz. A/B/G/N/AC, out of which, $802.11 \mathrm{~N}$ is mostly used. $\mathrm{N}$ standard $\mathrm{Wi}-\mathrm{Fi}$, which uses $2.4 \mathrm{GHz}$ band had no interference problem because of a small number of users in the beginning. However, recently the use of wireless $\mathrm{Wi}-\mathrm{Fi}$ increased rapidly, and the distance of transmission range also became longer than that used for $802.11 \mathrm{~B}$ and $\mathrm{G}$, which causes degradation in the signal quality due to interference by long-distance signals.

Table 1. Wi-Fi Channel Frequencies

\begin{tabular}{|c|c|c|c|c|c|}
\hline \multicolumn{2}{|c|}{$\begin{array}{c}\text { 2.4 GHz } \\
\text { Frequency } \\
\text { Domain }\end{array}$} & \multicolumn{4}{|c|}{$\begin{array}{c}\text { 5 GHz } \\
\text { Frequency } \\
\text { domain }\end{array}$} \\
\hline $\begin{array}{c}\text { Channel } \\
\text { Number }\end{array}$ & $\begin{array}{c}\text { Frequency } \\
(\mathrm{GHz})\end{array}$ & $\begin{array}{c}\text { Channel } \\
\text { Number }\end{array}$ & $\begin{array}{c}\text { Frequency } \\
(\mathrm{GHz})\end{array}$ & $\begin{array}{c}\text { Channel } \\
\text { Number }\end{array}$ & $\begin{array}{c}\text { Frequency } \\
(\mathrm{GHz})\end{array}$ \\
\hline 1 & 2.412 & 34 & 5.170 & 108 & 5.540 \\
\hline 2 & 2.417 & 36 & 5.180 & 112 & 5.560 \\
\hline 3 & 2.422 & 38 & 5.190 & 116 & 5.580 \\
\hline 4 & 2.427 & 40 & 5.200 & 120 & 5.600 \\
\hline 5 & 2.432 & 42 & 5.210 & 124 & 5.620 \\
\hline
\end{tabular}




\begin{tabular}{|l|l|l|l|l|l|}
\hline 6 & 2.437 & 44 & 5.220 & 128 & 5.640 \\
\hline 7 & 2.442 & 46 & 5.230 & 132 & 5.660 \\
\hline 8 & 2.447 & 48 & 5.240 & 136 & 5.680 \\
\hline 9 & 2.452 & 52 & 5.260 & 140 & 5.700 \\
\hline 10 & 2.457 & 56 & 5.280 & 149 & 5.745 \\
\hline 11 & 2.462 & 60 & 5.300 & 153 & 5.765 \\
\hline 12 & 2.467 & 64 & 5.320 & 157 & 5.785 \\
\hline 13 & 2.472 & 100 & 5.500 & 161 & 5.805 \\
\hline- & - & 104 & 5.520 & 165 & 5.825 \\
\hline
\end{tabular}

\section{Network Selection Algorithm at the Starting Point of Mobile Device}

It is expected that a next generation network will have multiple layers of various wireless access nets. In such a scenario, the bandwidth and the service range of each network should be identifiable for an effective selection of network by the users, who want to move to other networks and still receive a seamless service through analysis of the network features. As Figure $\mathrm{x}$ shows that, a user near an AP is able to use a fast telecommunication and it steadily becomes slower as the AP goes farther from the user. Generally, a minimum bandwidth for each module is required for the data to reach a user, so that the user can watch movies, send/receive voice data or check e-mail through Internet.

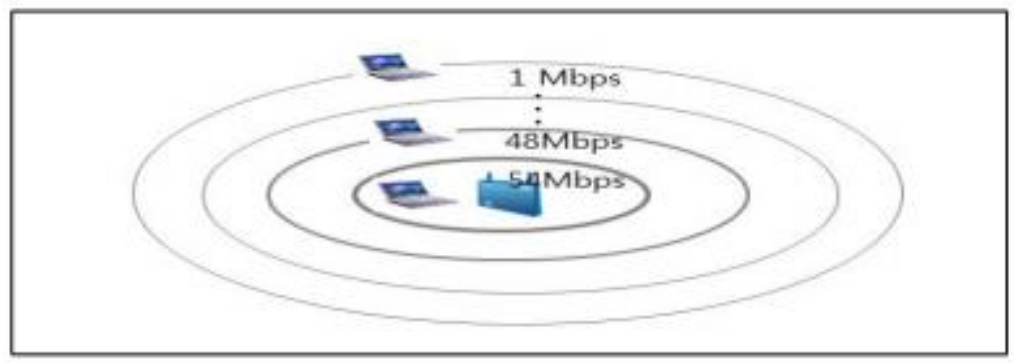

Figure 3. Multi Rates of Wireless LAN

Bandwidth refers to the difference between the maximum and the minimum frequencies of a signal that can be used in the network, which in other words, is the maximum transmission rate available in the communication, i.e., the capability to send data. Its basic unit is bps. The transmission system of a TV signal that sends 30 frames per second requires a bandwidth of $6 \mathrm{MHz}$ and the data transfer rate is determined by valid bandwidth and signal-to-noise ratio. Formula 1 and 3 is Shannon's law that decides the bandwidth, where $C$ is the capacity, $B$ is the bandwidth, and $S / N$ is the signal-to-noise ratio.

$$
\begin{gathered}
C=B * \log (1+S / N) \\
B=C / \log (1+S / N)
\end{gathered}
$$


Table 2 lists the telecommunication rate per RSSI at the bandwidth of $2.4 \mathrm{GHz} / 5 \mathrm{GHz}$. It was found that the rate becomes slower as RSSI decreases. This suggests that, when the signal of a wireless network, connected to a laptop or a mobile terminal that is used by a person watching TV, is 81 or lower, the TV is not receiving a good signal.

Table 2. Rate per RSSI at 2.4G/5G

\begin{tabular}{|c|c|c|c|c|c|c|}
\hline 802.11 a Rate(Mbps) & 6 & 18 & 24 & 36 & 48 & 54 \\
\hline $\begin{array}{c}\text { Received signal strength } \\
(\mathrm{dBm})\end{array}$ & -81 & -78 & -75 & -76 & -73 & -71 \\
\hline $\begin{array}{c}802.11 \mathrm{~b} / \mathrm{g} \text { Rate(Mbps) } \\
\text { Received signal strength } \\
(\mathrm{dBm})\end{array}$ & -81 & -78 & -75 & -75 & -72 & -71 \\
\hline
\end{tabular}

Table 3. Access Source Code for Automatic Connection

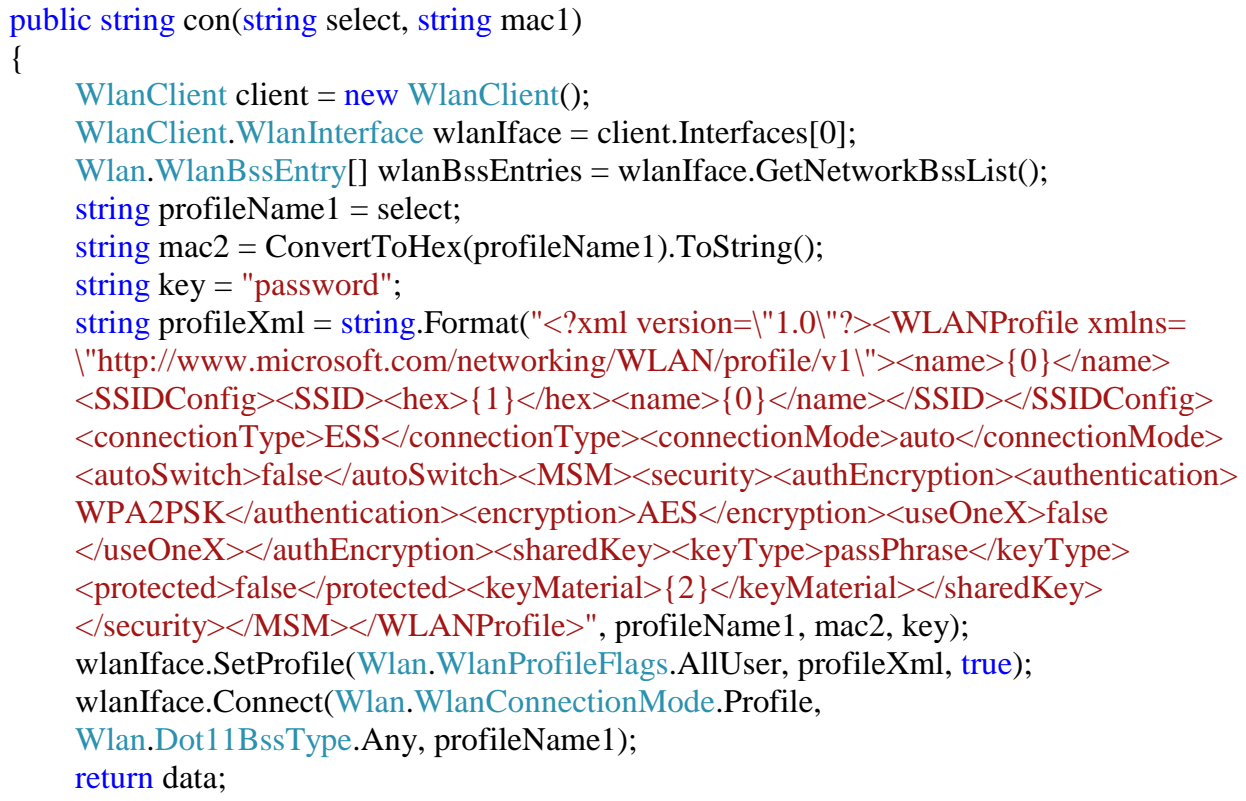

The current study proposes an algorithm for a mobile device that can select a safe network in advance after estimating the transfer rate by using the received RSSI value to solve the problem. The suggested algorithm can find all the APs that can use both $2.4 \mathrm{GHz}$ and $5 \mathrm{GHz}$ around initially or a single-frequency band, then compare their RSSI, select the AP with the highest RSSI, receive data, such as SSID, MAC address, RSSI and Frequency domain, and finally can gain access using the source codes of Table 3.

The proposed algorithm is able to perform the following functions sequentially-

a) Find all the APs that can use both $2.4 \mathrm{GHz}$ and $5 \mathrm{GHz}$ around initially or a singlefrequency band

b) Compare their RSSI and select the AP with the highest RSSI 
c) Receive data, such as SSID, MAC address, RSSI and the Frequency domain

d) Can gain access using the source codes of Table 3

When the transfer rate is similar to or lower than that needed to transmit the data, the AP with the highest RSSI in the current position is selected. In this regard, it can be mentioned that, a lower transfer rate occurs if the mobile device moves to a place, which either is beyond the AP coverage zone or has a bad transmission factor of the AP signal. Figure 4 shows the network selection algorithm flowchart proposed in this paper.

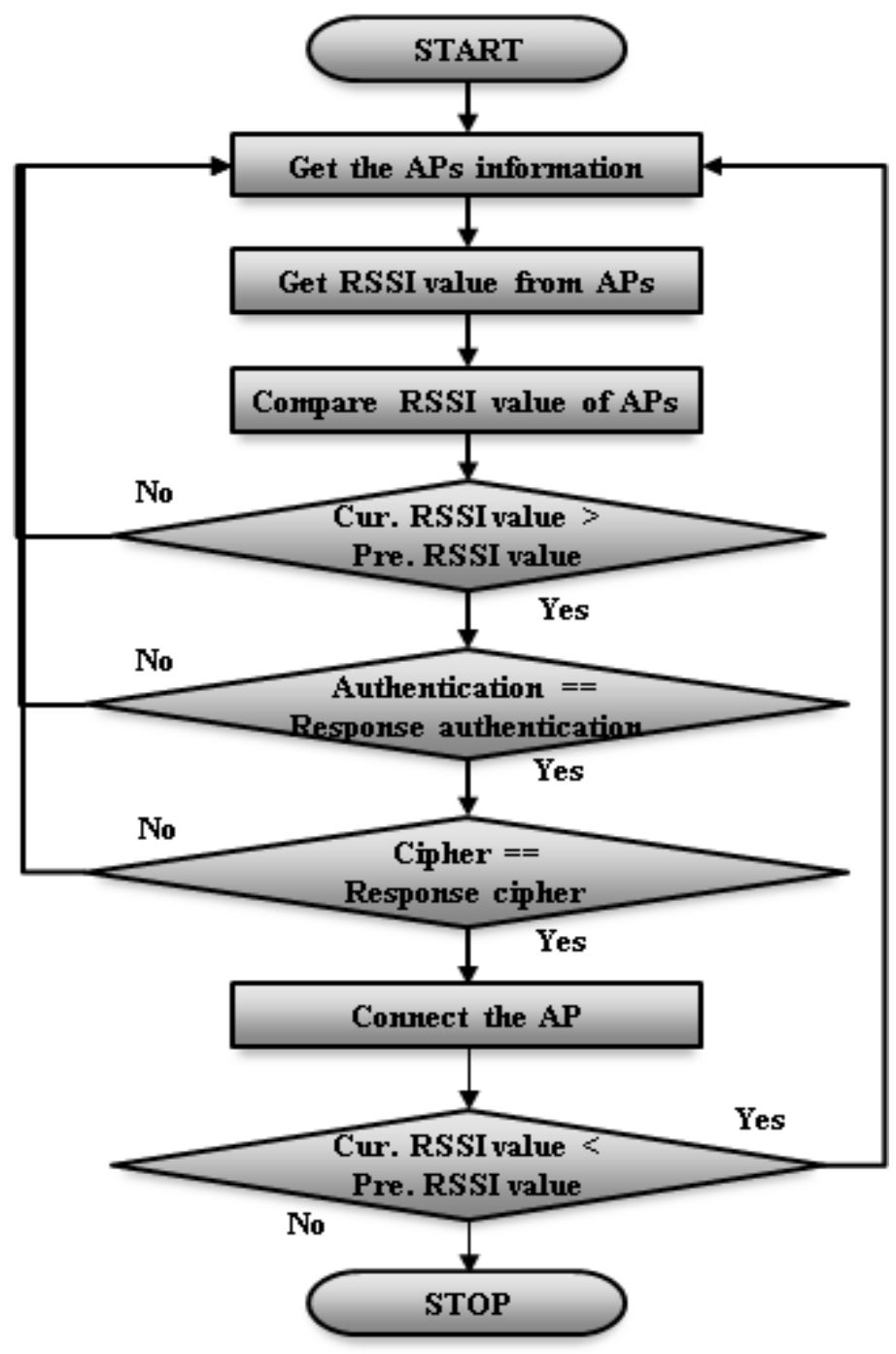

Figure 4. Flowchart of Network Selection Algorithm at the Starting Point of a Mobile Device

\section{Test Environment and Performance Analysis}

\subsection{Test Environment}

The test used to analyze the performance of the proposed technique has been presented in this section. First, the test components are shown in Table 4. 
Table 4. Test Components and Setup

\begin{tabular}{|c|c|}
\hline Division & Description \\
\hline AP Type & $\begin{array}{c}\text { ipTIME A2004N5, } \\
\text { ipTIME N500U }\end{array}$ \\
\hline Tool used & Visual studio2012, \\
\hline Language used & C\# \\
\hline Laptop & Samsung Sense R530 \\
\hline
\end{tabular}

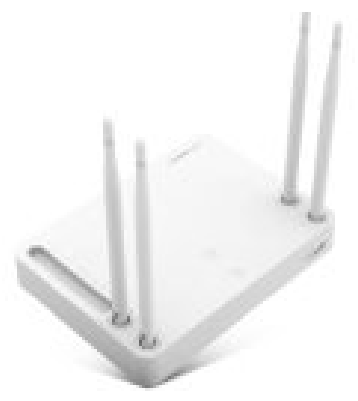

(a) USB Wireless LAN

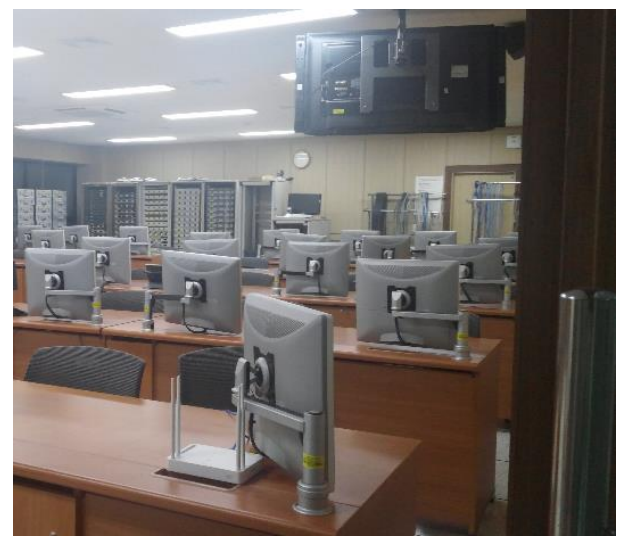

(d) Lecture room

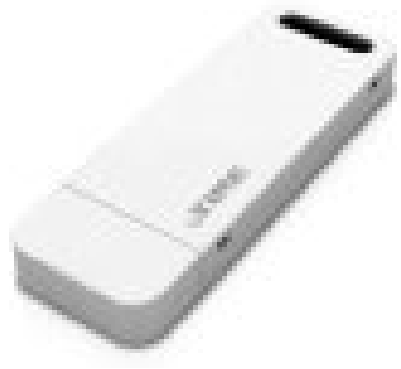

(b) Wireless router

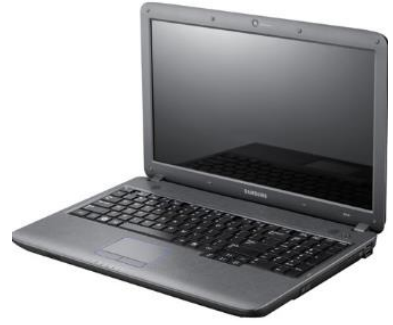

(c) Laptop

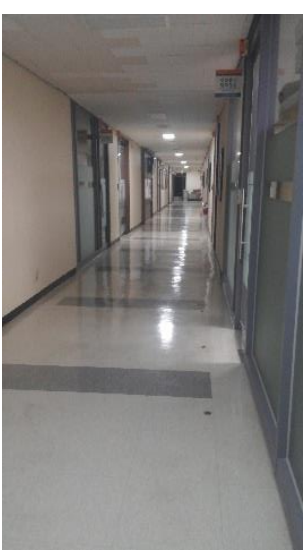

(e) corridor

Figure 5. Different Test Components to Evaluate Performance

Figure 5 presents USB Wireless LAN, wireless router and laptop used for the test. (a) is USB LAN provided by ipTIME, which was inserted into (c), while (b) is the wireless router also provided by ipTIME. (d) is where the router is installed and (e) was repeatedly visited for the test. 


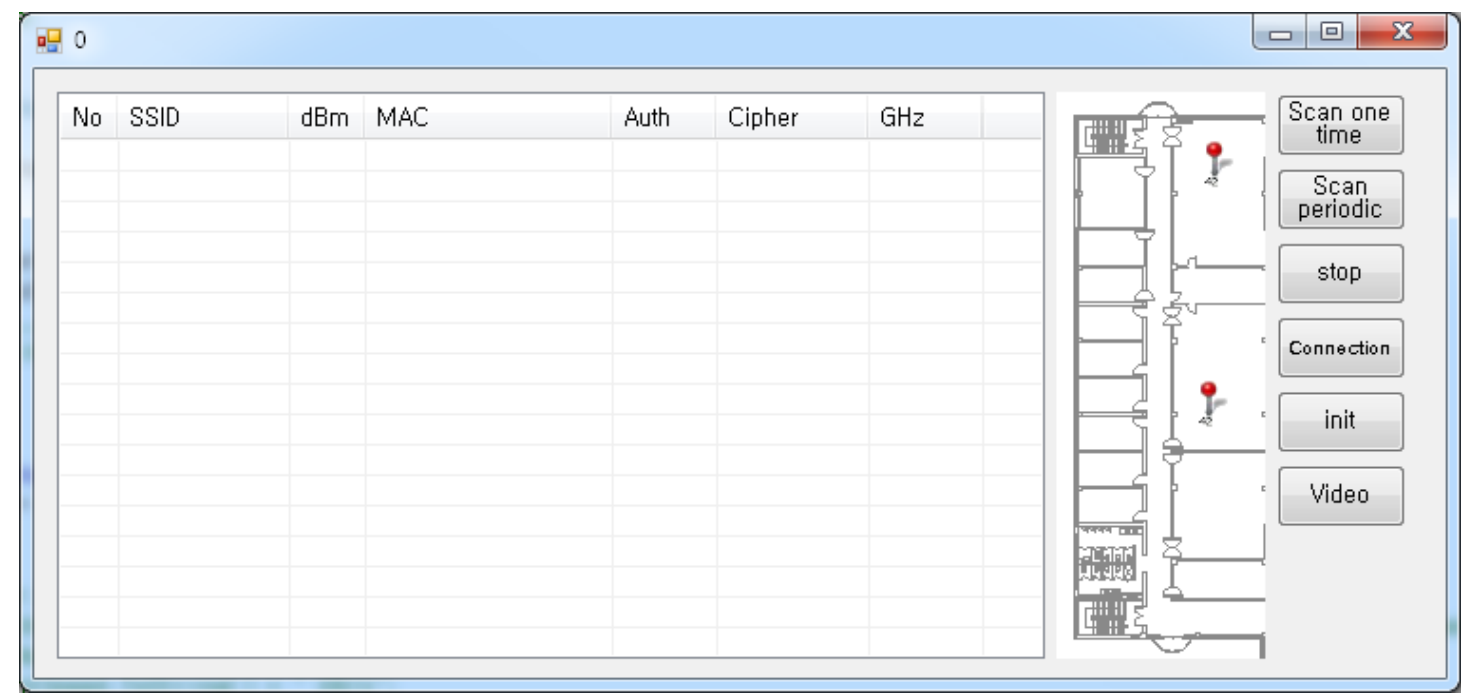

(e) Main Screen

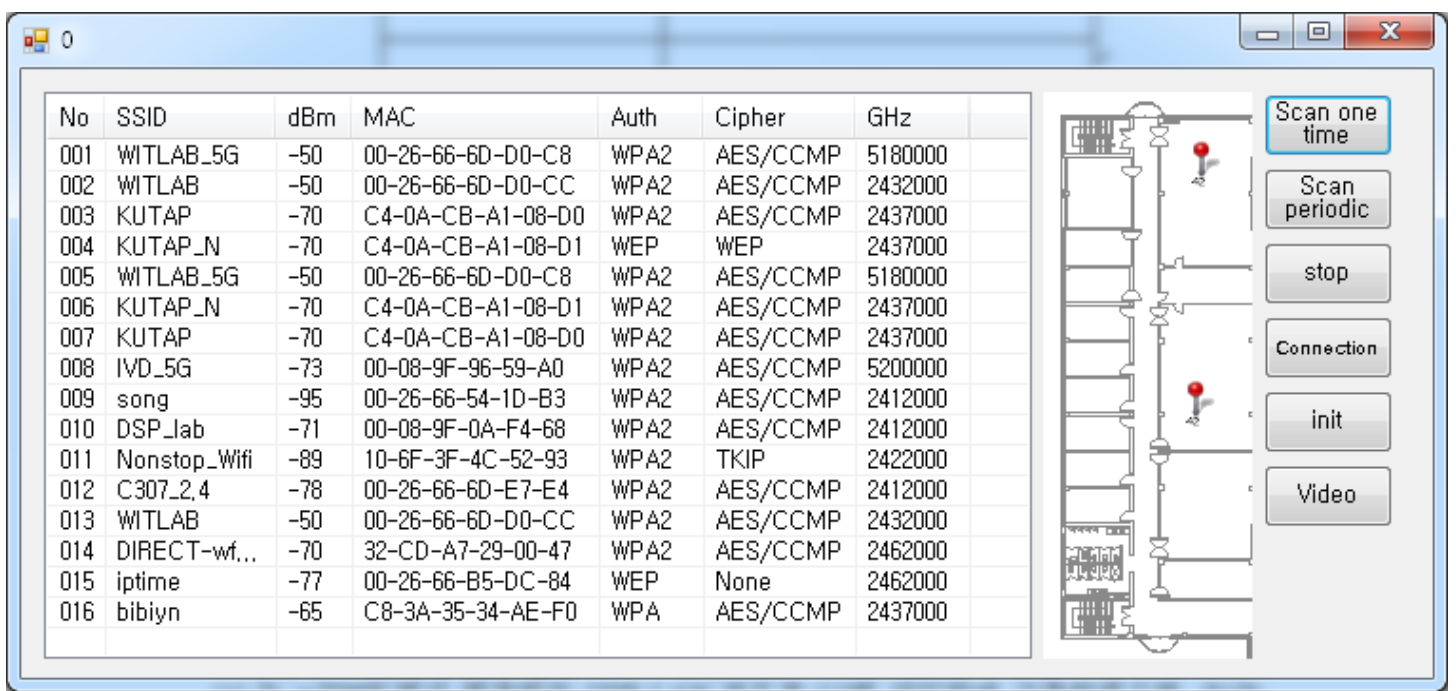

(b) Screen that Collect Data from the Wireless Routers

Figure 6. Data Collection Software

Figure 6 shows the screenshots of the software that has been used to collect and access the data on the laptop, with which two wireless routers of ipTIME were connected and multiple unidentified router signals were received. To visualize the data collection process, the collection software was operated with visual studio 2012 and C\#. (a) of Figure 6 is the main screenshot and can search AP that can use both $2.4 \mathrm{GHz}$ and $5 \mathrm{GHz}$ around initially. (b) is the screenshot that collects data from the wireless routers and shows the routers' SSID, RSSI, MAC address, authentication, cipher and frequency that were searched around.

\subsection{Performance Analysis and Review}

To analyze the suggested network selection algorithm, a test was conducted at the fourth floor corridor of the first engineering building Koreatech. 


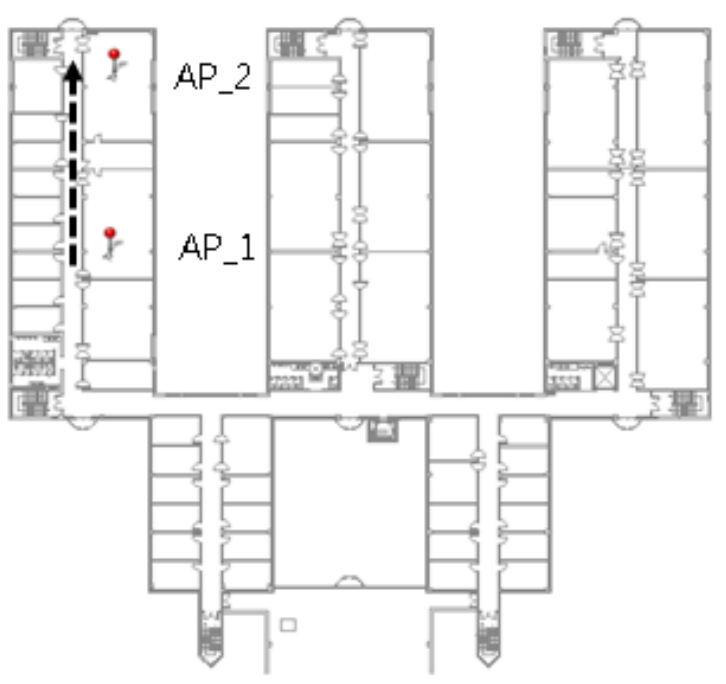

Figure 7. The Test Location

Figure 7 shows a schematic diagram of the test location, where the changes of RSSI with distance were tested by using AP and mobile devices. The test measured the RSSI for AP_1 and AP_2 by moving along the arrow direction of Figure 7.

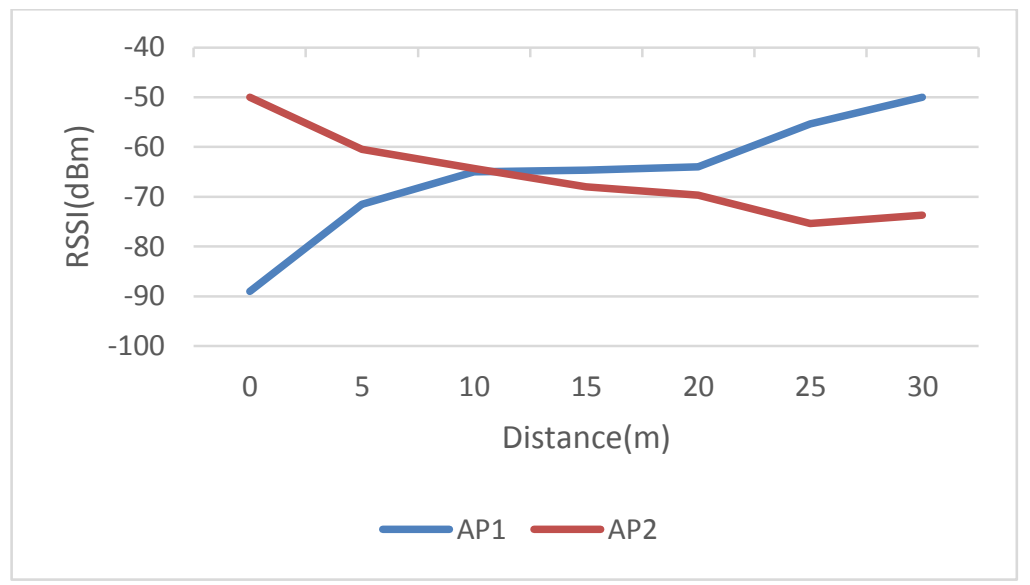

Figure 8. Environment that Tested Changes of RSSI with Distance using AP and Mobile Devices

Figure 8 is the graphic representation of the RSSI value obtained from the abovementioned test and shows the average value of RSSI measured ten times, with every time moving along the arrow direction of Figure 7. It was found that the RSSI value of AP1 increased, whereas for AP2 decreased with increase in distance and both attain the same value at $10 \mathrm{~m}$. 


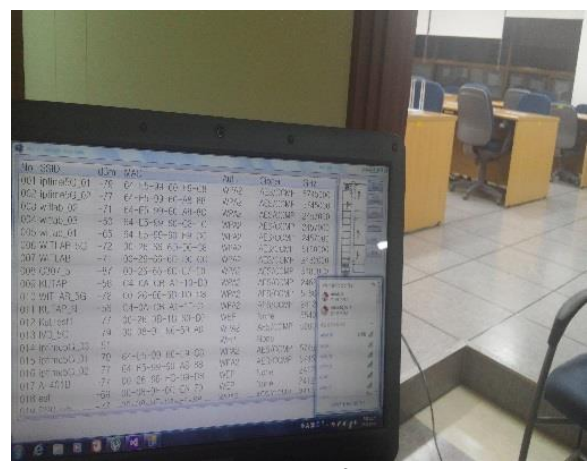

(a) $0 \mathrm{~m}$

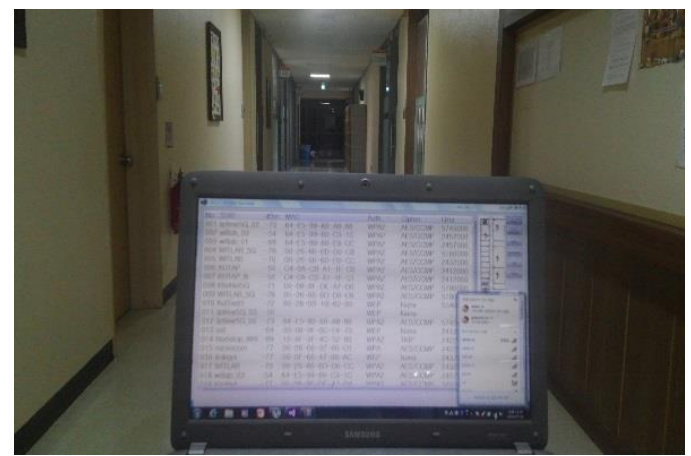

(b) $10 \mathrm{~m}$

Figure 9. Confirmation whether Hand-over Occurs with a Change in Distance or Not

Figure 9 confirms whether a hand-over technology occurs with a change in distance or not. At the starting point of $0 \mathrm{~m}$, the laptop was connected to AP_1 of Figure 7 and moved to the lecture room that has AP_2. As Figure 8 shows, it was found that the laptop connected to the initial AP_1 has been transferred to AP_2 at $10 \mathrm{~m}$.

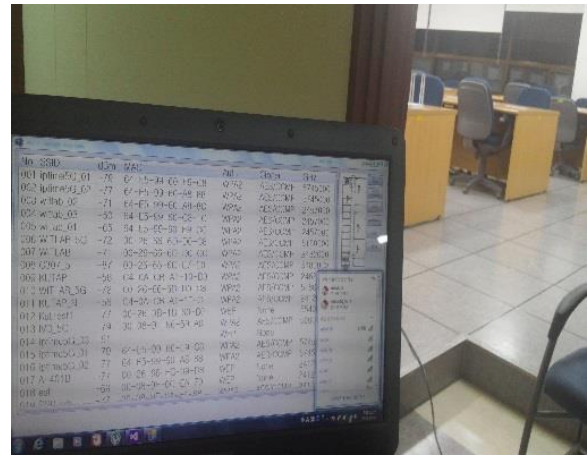

(a) $0 \mathrm{~m}$

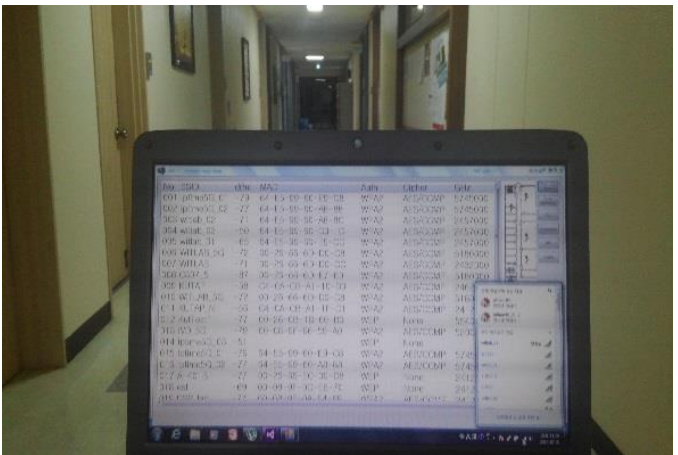

(b) $8 \mathrm{~m}$

\section{Figure 10. Confirmation whether Hand-over Occurs with a Change in Distance or Not, while Media-service is in Use}

Figure 10 shows whether hand-over occurs with a change in the distance or not, while media-service is in use. The laptop was connected to AP_1 of Figure 7 at the starting point of $0 \mathrm{~m}$ and moved to the lecture room that has AP_2. Though Figure 9 illustrates hand-over occurred from AP_1 to AP_2 at $10 \mathrm{~m}$, Figure 10 shows it occurred at $8 \mathrm{~m}$ from AP_1 to AP_2.

\section{Conclusion}

The location estimation technology, using WLAN is mostly based on mobile devices with a good portability. The hand-over technology is typically controlled and managed at the server to identify AP information and select a network quickly. Though this is the best choice to select network and connect communication quickly, any mobile device that is not registered in the server cannot be provided with the service. This paper suggested a network selection algorithm at the starting point of mobile device to solve the problem. The test results 
show that, hand-over occurred at the locations that have the exact opposite RSSI value in motion using two APs and it also occurred as usual while a media-service is in use.

\section{Acknowledgements}

This research was supported by the MSIP (Ministry of Science, ICT \& Future Planning), Korea, under IT/SW Creative research program supervised by the NIPA (National IT Industry Promotion Agency)" (NIPA-2013-(H0502-13-1082))

\section{References}

[1] J. Hightower and G. Borriello, "Location System for Ubiquitous Computing", IEEE Computer Society, vol. 34, no. 8, (2001), pp. 57-66.

[2] W. Lee and H. Lee, "Performance Evaluation of Coordinated Multi-Point Transmission and Reception in Indoor Mobile Communication Systems", Journal of information and communication convergence engineering, vol. 11, no.3, (2013), pp.167-172.

[3] B. H. Li, J. Salter, A. G. Dempster and C. Rizos, "Indoor Positioning Techniques Based on Wireless LAN", Proc. First IEEE Int'l Conf. Wireless Broadband and Ultra Wideband Comm., (2006).

[4] Y. Gu, A. Lo and I. Niemegeers, "A Survey of Indoor Positioning Systems for Wireless Personal Networks", IEEE Communications Surveys \& Tutorials, vol. 11, no. 1, (2009).

[5] R. Want, A. Hopper, V. Falcao and J. Gibbons, "The Active Badge Location System", ACM Transactions on Information System, vol.10, no.1, (1992), pp.91-102.

[6] M. Rodriguez, J. P. Pece and C. J. Escudero, "In-building location using Bluetooth", Proc. IWWAN, (2005).

[7] IEEE 802.21, "IEEE 802.21 Media Independent Handover," vol. 2006: IEEE 802.21, pp. http://www.ieee802.org/21/

[8] P. A. Pangalos, "End-to-end SIP based real time application adaptation during unplanned vertical handovers", Proc. IEEE Global Telecommunications Conference, (2001); San Antonio, Texas, USA.

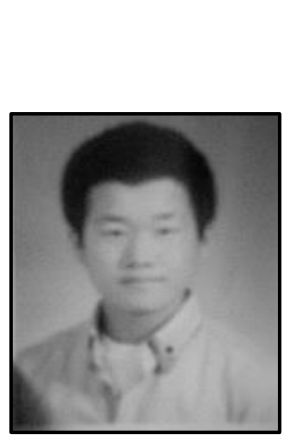

\section{Authors}

Hyun-Jun Shin received a B.S degree in the Department of electrical engineering from Namseoull university, Cheonan, Korea, in 2011 and an M.S. degree in Electrical, Electronics and Communication Engineering at the Korea University of Technology and Education, Cheonan, Korea, in 2011. He is currently pursuing a Ph.D. degree in Electrical, Electronics and Communication Engineering at the Korea University of Technology and Education, Cheonan, Korea. His research interests are in the wireless sensor network, wireless localization, channel coding.

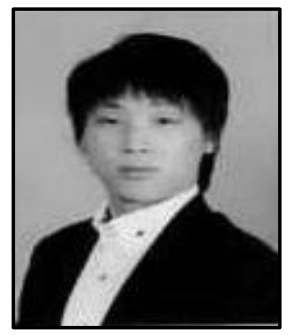

Min-Ho Jeon received the B.S degree in the Department of Game Digital Content from Far East University, Umsung, Korea, in 2009, and an M.S. degree in Electrical, Electronics and Communication Engineering at the Korea University of Technology and Education, Cheonan, Korea, in 2011. He is currently pursuing a Ph.D. degree in Electrical, Electronics and Communication Engineering at the Korea University of Technology and Education, Cheonan, Korea. His research interests are in the context-aware, wireless sensor network, wireless localization, channel coding and M2M network. 


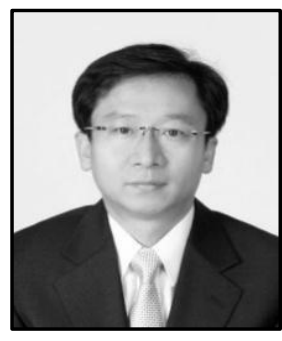

Chang-Heon Oh received the B. S. and M.S.E. degrees in telecommunication and information engineering from Korea Aerospace Univ. in 1988 and 1990, respectively. He received the $\mathrm{Ph} . \mathrm{D}$. degree in avionics engineering from Korea Aerospace Univ., in 1996. From Feb. 1990 to Aug. 1993, he was with Hanjin Electronics Co. From Oct. 1993 to Feb. 1999, he was with the CDMA R\&D center of Samsung Electronics Co. Since Mar. 1999, he has been with the School of Electrical, Electronics and Communication Engineering, Korea University of Technology and Education, where he is currently a professor. His research interests are in the areas of wireless communications, mobile communication, and wireless sensor networks with particular emphasis on wireless localization. 